\title{
Research on Equitable Education in Urban and Rural China
}

\author{
Jiaqi $\mathrm{Wu}^{1 *}$ \\ ${ }^{1}$ Experimental middle school, JinTang, SiChuan, 610400, China \\ *Corresponding author. Email:chichi1205@qq.com
}

\begin{abstract}
Science and education revitalize the country and strengthen the country through human resources. Education, as the foundation of scientific and technological development and talent training, has been attached great importance by all countries in recent years, and fair education has also become the goal pursued by all countries in the world. After the founding of New China, under the strategic background of priority development of urbanization, China has formed a dual social structure of urban and rural areas, resulting in a huge gap between urban and rural residents in all aspects, especially in the field of education. This paper analyzes the current situation from the perspective of national conditions. Analyze the existing problems at the present stage, and explore the sustainable and effective development path. Centering on "fair education, current situation and development of urban and rural education". This paper holds that education is unfair because the starting point of education of urban and rural residents is unfair. The gap between the rich and the poor caused by the leading or lagging local development is a real obstacle to fair education, and at the same time causes the difference in educational concepts. The dual social structure of the city leads to the uneven allocation of resources, which further aggravates the degree of unfairness in education. The unbalance of education development is the direct result of the unfairness in education. The paper continuously asks the importance of fair education in practical problems and conclusion that it is necessary to establish the concept of fair education for different classes at present, so as to provide spiritual and material guarantee for the development of disadvantaged classes.
\end{abstract}

Keywords: Social equity, Urban and rural education, Educational equity, Urban-rural gap

\section{INTRODUCTION}

The construction of a harmonious society puts forward higher requirements for education, harmonious society is inseparable from harmonious education. However, because of the development of China's education, people have to face another scene, the public opinion has pointed to the reality of education is not quite harmonious, that is, the unbalanced development of education, especially the issue of educational fairness, caused widespread and high attention of people[1].

Through the experience of supporting education in rural areas, the author finds that there is a huge gap between urban and rural education development, which triggers deep thinking. On the topic of education equity, the Chinese government has proposed "promoting the equitable development and quality improvement of education" in the 2015 Government Work Report[2]. It is not hard to find that education is the driving force of social development, the main way to improve the comprehensive quality of the people and promote national development. Education equity is the premise of social equity. At present, urban and rural education inequality has seriously affected China's economic and social development. Therefore, the study of urban and rural education equity has important practical significance.

Under such a realistic background, this paper makes a profound analysis of the current situation of inequality in urban and rural education in China, and tries to find out the problems and seek more effective ways to achieve equality in urban and rural education.

\section{THE IMPORTANCE OF EQUITY IN EDUCATION}

In today's society with the rapid development of urban construction, urban teenagers with superior 
resources and deep cities often have questions when they see the news about rural education. Under the same blue sky, are rural teenagers living completely different lives as reported in the news?The author had the same question before he went to a rural primary school in Sichuan to help teach.

In fact, the content reported by the news is only the tip of the iceberg of rural education problems. The unfairness of education caused by the unfairness of social development has left deep traces in this small village.

And education does not have class and grade sex from the time it comes into being. Primitive society had no class nature, no differentiation from social life and life, no specific education places and full-time education personnel, so the education at that time was classless. It is not difficult to conclude that educational equity is the concrete embodiment of social equity, but also an important cornerstone of national development.

The realization of education equity is a good vision of all mankind, because education itself has a special social function. The economic and technological development of modern society depends on the support of education. In a society full of signs of inequality, education can help the disadvantaged improve their living conditions and give them opportunities for upward mobility. Therefore, educational equity is the tool to break class society, and only educational equity can achieve social equity[3].

Educational equity is not a new topic, ancient sages have discussed it. As early as in the late Spring and Autumn period of China, the educator Confucius once proposed that everyone enjoys the equal right to education. It created a precedent for educational equity in China. In the west, Aristotle, a thinker, also proposed to guarantee the educational rights of free people by law. Later, Professor Coleman of the United States published his report "The Concept of Equal Educational Opportunities", in which he believed that educational fairness mainly contains four meanings: one is to provide free education to people up to a certain level;second, to provide a common curriculum for all children, regardless of their social background;third, to provide opportunities for children from different social backgrounds to attend the same schools;fourthly, educational opportunities are equal in the same characteristic areas[4]. However, modern society has not been as simple as at the beginning of the environment, different historical periods, about the education of equity, its connotation is different, the form of expression is not the same, of course, can not copy the previous theory to develop the present education. Back in modern times, rural areas, which had to lag behind for the sake of urban development, must find new and adaptable ways to promote educational equity.

\section{THE REASONS FOR UNFAIRNESS IN URBAN AND RURAL EDUCATION}

\subsection{Unfair Starting Point for Education}

The main premise of education fairness is the fair starting point. Only by the point of view of urban and rural education is the starting point of the urban and rural education to link the urban and rural education to fairness. In order to popularize education, China has implemented the policy of "universal obligation education". Since 1965, China's urban construction has achieved certain achievements in the long run. But at the same time, the enrollment rate for rural compulsory education is still low, the enrollment rate is low, and the dropout rate is high. This widened the gap between urban and rural education.

\subsection{Influenced by Family Values}

The root cause of this policy is that rural teenagers are influenced by family perceptions. Some families are conservative and outdated, so they think that learning knowledge is empty, useless, unable to change the status quo, it is not the energy to change the fate, and it is best to help the family share the labor, become the productivity, and start to earn the family[5].

\subsection{Affected by Economic Factors}

The other part of the family, again affected by the economy. Parents want to let their children receive education, thanks to the government's"compulsory education"policy, for them to avoid tuition and miscellaneous fees, but there are some other expenses, forced by the poor family environment, which cannot support their children to receive the education.

\subsection{Status of Urban Education}

Education resources are extremely rich in cities, but family education level is higher, so the city youth can not only finish the compulsory education, and even can choose the best option, create better education conditions for the child, the child's every stage of learning as a key investment, make sure that the children accept education, accept the best education. This has led to a gap between urban and rural education, not only in enrolment rates, but also in the quality of education.

\subsection{Specific Reasons for Unfairness}

However, educational equity is not just an opinion, it is an issue that needs to be examined comprehensively. The quality of education is determined by the process of education, and the process of education is mainly reflected in: hardware equipment, teachers. 


\subsection{About Hardware}

It is not hard to find from field visits that many rural primary schools do not even have the most basic conditions for running schools. The school buildings were dilapidated, the desks and chairs were in disrepair and the necessary stationery was lacking. According to the survey, about $49 \%$ of middle school buildings and $82 \%$ of primary school buildings in rural China are dilapidated, while relevant data only account for $10 \%$ and $3 \%$ in urban areas [6]. In addition to school buildings, village schools lack playgrounds, libraries, multimedia equipment, Musical Instruments, laboratory supplies and sports equipment. Even when fully equipped, they have long since been damaged and unusable, and no one has provided them. This makes the channel for rural teenagers to acquire knowledge become single, but also lost the opportunity for all-round development.

\subsection{About Faculty}

In addition to material resources, teachers are also an important factor leading to education inequality between urban and rural areas. There is a huge gap between the education level and the comprehensive quality of teachers in the two places. Teachers with excellent backgrounds are concentrated in key urban schools. Even ordinary school children can consolidate their knowledge through weekend tutoring outside of school by famous teachers. In contrast, the education level of rural teachers lags far behind that of urban teachers, and due to the lack of human resources, it is common for schools to have the same teacher teaching multiple subjects, or the same teacher teaching students of different grades at the same time. Some teachers even have to take care of their students' lives. Low wages and heavy tasks exacerbate the loss of rural teachers, resulting in a weaker contingent of rural teachers. Unbalanced development is the direct result of unfairness in education.

\section{MEASURES FOR IMPLEMENTING EDUCATION IN URBAN AND RURAL AREAS}

\subsection{Change Ideas}

Equity in education is not a new topic, and equitable education in urban and rural areas is also an issue that has been explored all the time. However, there has been no substantial progress in recent years, which cannot be separated from practical factors: the gap between urban and rural economic development is gradually widening, and the whole society has not paid enough attention to it. Therefore, if we want to realize the equality of urban and rural education, we must change our concept and lead qualitative change in action. The first is to eliminate the superiority of the urban population and enhance the confidence of the rural population in future development.

\subsection{Safeguarding the Rights and Interests of Rural Residents}

we should change the concept of rural development giving way to urban development, treat residents of both places equally, guarantee the rights and interests of rural residents, and even help rural development more. Only when the social status is equal can the educational equity of the two places be better achieved.

\subsection{Increase Investment in Rural Education}

After changing the concept of valuing city over the country, we should increase the investment in rural education. We will improve educational facilities, ensure that rural students have safe and comfortable school buildings, and introduce modern teaching equipment to gradually narrow the gap between urban and rural areas. At the same time, teachers' salaries should be appropriately raised to retain talents and attract more teachers with excellent backgrounds to teach courses in rural areas. We will carry out more volunteer teaching activities in rural areas to provide students from both urban and rural areas with opportunities to communicate and learn.

\subsection{Ensure the Stability of Family Economic Income}

The other is to ensure stable economic income for the family. We will vigorously support the development of rural productivity and maximize the development of the rural economy. The economic foundation determines the superstructure. Only when the economy is guaranteed can the problem of basic education expenditure be solved. Only then can more people be willing to invest in education and abandon the outdated ideas fundamentally, so as to directly narrow the gap between urban and rural education.

\section{CONCLUSION}

First, we need to change the concept of rural areas evaluating cities. Second, we need to increase investment in rural education. Third, we need to increase teachers' salaries. Fourth, ensure the stable income of rural households. On the issue of education equity between urban and rural areas, the discussion in this paper is still at the basic comparative level and lacks professional theory. In the future, the author will devote himself to the study of education, hoping to acquire more accurate and professional theoretical knowledge, so as to expand his professional theory of urban and rural educational rights and interests. At the same time, I 
will continue to participate in different areas of rural voluntary education, and analyze the issue of education equity between urban and rural areas from more perspectives.

\section{ACKNOWLEDGMENT}

First of all, I'd like to thank Professor Liam Gearon of Oxford University. Professor Liam Gearon has put a lot of effort into the topic selection, thinking and writing of this paper. His rigorous academic attitude, profound professional knowledge and diligent dedication have given me great inspiration and inspiration.

Secondly, I would like to thank all the teachers and students in a village primary school in Sichuan. The volunteer teaching experience made me meet you, which gave me this profound thinking and made this paper.

On the occasion of the completion of the thesis, I would like to express my heartfelt thanks to all the teachers and students who have given me guidance, help and support.

\section{REFERENCES}

[1]Hongyu Zhou. (2005)Educational fairness: the important content, foundation realization and way of harmonious society. The people's education. The seventh period.

[2]Keqiang Li. (2015)The third Session of the 12th National People's Congress. Beijing. 1.

[3]Xin Liu. (2008)From Education Policy to Education Equity -- Research on the Equity Mechanism of China's Basic Education Policy. Central China Normal University Press. 1:28.

[4]Wenyan Weng. (2003)Educational equity and school choice system. Beijing Normal University Press. 3-4.

[5]Chenqing Li. (2015)Study on education equity in Urban and rural areas. Shanxi University of Finance and Economics Press. 4: 26-27.

[6]Guojun Zhao. (2009)Study on education equity in Urban and rural areas of China. Hunan Normal University Press. 15. 